Review Article

\title{
3D Printing Manufacturing Techniques, Materials, and Applications: An Overview
}

\author{
D. Srinivasan, ${ }^{1}$ M. Meignanamoorthy, ${ }^{1}$ M. Ravichandran $\left(D,{ }^{1}\right.$ V. Mohanavel $(D), 2$ \\ S. V. Alagarsamy, ${ }^{3}$ C. Chanakyan, ${ }^{4}$ S. Sakthivelu, ${ }^{5}$ Alagar Karthick ${ }^{(D)}{ }^{6}$ T. Ram Prabhu, ${ }^{7}$ \\ and S. Rajkumar ${ }^{8}$ \\ ${ }^{1}$ Department of Mechanical Engineering, K.Ramakrishnan College of Engineering, Trichy 621112, Tamilnadu, India \\ ${ }^{2}$ Centre for Materials Engineering and Regenerative Medicine, Bharath Institute of Higher Education and Research, \\ Chennai 600073, Tamil Nadu, India \\ ${ }^{3}$ Department of Mechanical Engineering, Mahath Amma Institute of Engineering and Technology, Pudukkottai 622101, \\ Tamil Nadu, India \\ ${ }^{4}$ Department of Mechanical Engineering, Government College of Engineering, Thanjavur 613402, Tamil Nadu, India \\ ${ }^{5}$ Department of Mechanical Engineering, Mount Zion College of Engineering and Technology, Pudukkottai 622507, \\ Tamil Nadu, India \\ ${ }^{6}$ Renewable Energy Lab, Department of Electrical and Electronics Engineering, KPR Institute of Engineering and Technology, \\ Coimbatore 641407, Tamil Nadu, India \\ ${ }^{7}$ Centre for Military Airworthiness and Certification (CEMILAC), Defence Research and Development Organisation (DRDO), \\ Bangalore 560075, Karnataka, India \\ ${ }^{8}$ Department of Mechanical Engineering, Faculty of Manufacturing, Institute of Technology, Hawassa University, \\ Awasa, Ethiopia
}

Correspondence should be addressed to M. Ravichandran; smravichandran@hotmail.com and S. Rajkumar; rajkumar@hu.edu.et

Received 7 August 2021; Revised 4 September 2021; Accepted 9 November 2021; Published 10 December 2021

Academic Editor: Carlos R. Rambo

Copyright (C) 2021 D. Srinivasan et al. This is an open access article distributed under the Creative Commons Attribution License, which permits unrestricted use, distribution, and reproduction in any medium, provided the original work is properly cited.

3D printing, also called additive manufacturing (AM), is a method of creating 3D solid parts from a digital document. By utilizing additive routes, the fabrication of $3 \mathrm{D}$-printed objects can be made. These layers can be viewed as a gently cut level cross-area of the manifest object. 3D printing is somewhat in obstruction to subtractive manufacture, which is expelling/discharging out a touch of metal or plastic for the occurrence of a milling machine. 3D printing authorizes creating multifarious profiles employing fewer materials than conventional fabrication systems. This review article provides the general idea of 3D printing production techniques, materials used, and applications in the aircraft and automobile industry and biomedical fields.

\section{Introduction}

3D printing (or AM) is a procedure of linking materials to create parts from 3D model information, generally layer over layer. The component is designed using the CAD software, which is later sent out to a $3 \mathrm{D}$ printer. $3 \mathrm{D}$ printing gives a great deal of customization in component structure and could even print components, which cannot be produced by a few customary production methods. Difficult and complicated parts could be fabricated with a significant decrease in fabricating time, expenses, and material surplus [1]. 3D printing creates physical parts from a geometrical interpretation via advanced enlargement of materials. The $3 \mathrm{D}$ printing process is a quick developing process. Presently, 3D printing is generally utilized in the world. 3D printing process is more utilized for mass customization, making any sort of open-source plans in the farming, medicine, automobile, train, and flight sectors [2]. 3D printing or $\mathrm{AM}$ is a designing procedure utilized for delivering a 3D component layer over layer from a 
computerized 3D model according to the prerequisite. AM is a quicker fabricating method. The developing interest for $3 \mathrm{D}$ printing is a direct result of its favorable circumstances like quick prototyping and creating adjustable parts. The technique has now become one of the conventional production methods. Several materials having a place with many groupings such as composites, polymers, and ceramics could be used in ventures such as automation, aviation, medical services and clinics, gadgets, food, and some more [3]. The 3D printing method presents a frontline innovation in the territory of prototyping and component improvement method in the present production drift. Further, to overcome the goals of Industry 4.0 upset, mutually in the academic and industrialized sector, the interest in $3 \mathrm{D}$ printing is developing dramatically to use the merits of the method. Utilizing 3D printing fabricating methods, it is currently conceivable to construct the geometry of the confounded structure, which was very monotonous in the subtractive production method. 3D printing is characterized as the method where the $3 \mathrm{D}$ CAD model is finished into the component via saving material layer over the other [4]. The 3D printing process was developed in the 1980s, commonly notorious as AM. 3D printing has quickly accumulated broad concentration and created as a developing production method. Thus, it was broadly embraced in different fields, such as design gems, polymer printed materials, applied autonomy and mechanization, tissue and frameworks, and gadgets items. 3D printing helped the application fields as indicated by its few qualities, for example, brief timeframe process, minimal effort, customization, and material decrease. Besides, the $3 \mathrm{D}$ printing process is in the dynamic phase of mechanical development, which could propel the production, creation method, and fabrication development as an insurgency method [5].

\section{3D Printing Production Techniques}

Customary techniques for production want a serious extent of graceful supply chain management, need enormous work supremacy $3 \mathrm{D}$ printing process to be robotized, and depend on CAD programming to print items utilizing an assortment of materials, radically lessening the measure of supply chain management. When all is said in done, $3 \mathrm{D}$ printing does not utilize any expensive molds, nor does it need instruments, whichever for machining, structures, and punches, and it is an economical one. The $3 \mathrm{D}$ printing productions techniques are several depending on the sources. Based on the applications of the components, any one of the techniques can be selected. Figure 1 shows the classifications of $3 \mathrm{D}$ printing production techniques.

2.1. Powder-Based Systems. The powder-based system is one of the $3 \mathrm{D}$ printing production techniques. It uses regular and traditional inkjet print heads for the fabrication of components. Powder-based systems can be classified into four major categories: Laser Metal Deposition LMD, DMLS, SLM, and EBM.
2.2. Laser Metal Deposition (LMD). LMD is a 3D printing fabricating process that utilizes a laser beam to shape a pool of dissolved metal (a soften pool) outside a metallic substrate into which metal powder is infused utilizing a gas stream. Figure 2 shows the graphic illustration of the LMD method. The ingested metal powder makes a store on a superficial level. Regular applications incorporate the renovation of metallic parts, for example, form instruments, valves, worm screws. At first, the substrate is lighted by means of a laser beam, creating a liquefy puddle that catches and liquefies the powder elements passed up a nozzle. LMD uses different metals, and earthenware powder particles could be blended uniformly to get various composites ready through good properties. Then, powder particles are blended via fly of argon gases. By way of the laser source withdraws, the liquid pool hardens by means of warmth scattering via transmission, convection, and energy. The affidavit top, having the powder nozzle and optics for laser beam conveyance, goes beside the characterized way, thus framing a layer on the substrate. A short time later, the head passes up to the single-layer thickness for the deposition of the accompanying layer. In LMD, the principal layer is halfway reliquefied, filling in as another "substrate," subsequently assisting in the arrangement of the subsequent layer. A similar form of the $3 \mathrm{D}$ model is created in the CAD tool [6].

2.3. Direct Metal Laser Sintering (DMLS). DMLS is a method that permits the manufacture of difficult-formed objects from powder-based materials, as indicated via the $3 \mathrm{D}$ computer design. Figure 3 shows the graphic illustration of the DMLS method. DMLS is a laser-based $3 \mathrm{D}$ printing process, in which an entity is manufactured one layer over another utilizing powdered metal, radiant heaters, and a computer-operated laser. Fundamentally, the machine fabricates the entity on a transferable stage via smearing gradual layers of the design material. Intended for every layer, the machine sets out a film of powders, with a precise thickness $(0.1 \mathrm{~mm})$. At that point, a powerful laser beam is coordinated on a powder bed and modified to intertwine metal powders existing in its central region, as indicated by a computer-aided design document, in this manner producing a flimsy metal layer. The stage descends the prearranged layer thickness, a new film of powder is laid down, and the following deposit is softened with disclosure to the laser cause, so it adjusts to the past layer. Therefore, the procedure proceeds, one layer over another, till the component is manufactured [7].

2.4. Selective Laser Melting (SLM). SLM is a 3D printing method intended to utilize a high force thickness laser to liquefy and combine metallic powders. Figure 4 shows the graphic illustration of the SLM method. A part is worked by specifically dissolving and intertwining powders inside and amid layers. The SLM strategy is likewise generally called direct selective laser sintering, laser cussing, and direct metal laser sintering, and this method has been demonstrated to deliver close to the exact shape components up to $99.9 \%$ 


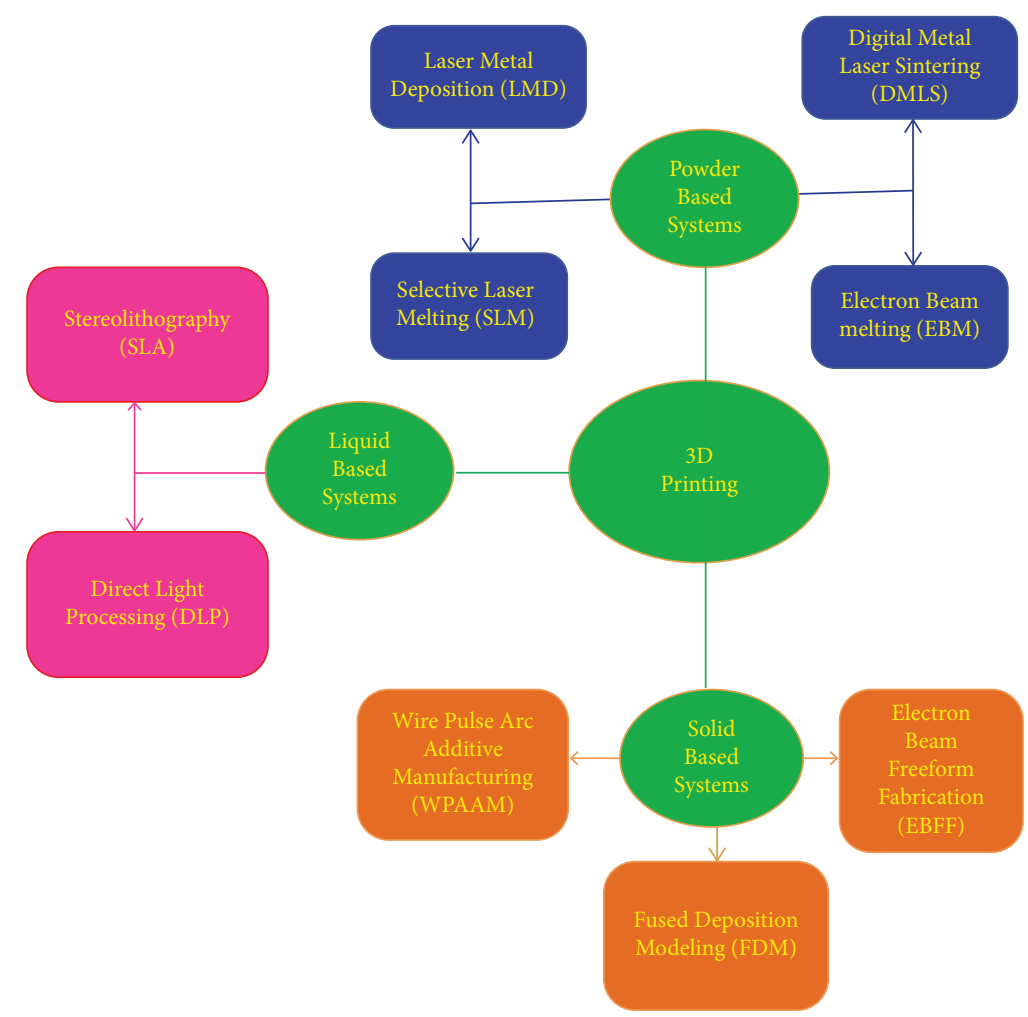

FIgURE 1: Classifications of 3D printing production techniques.

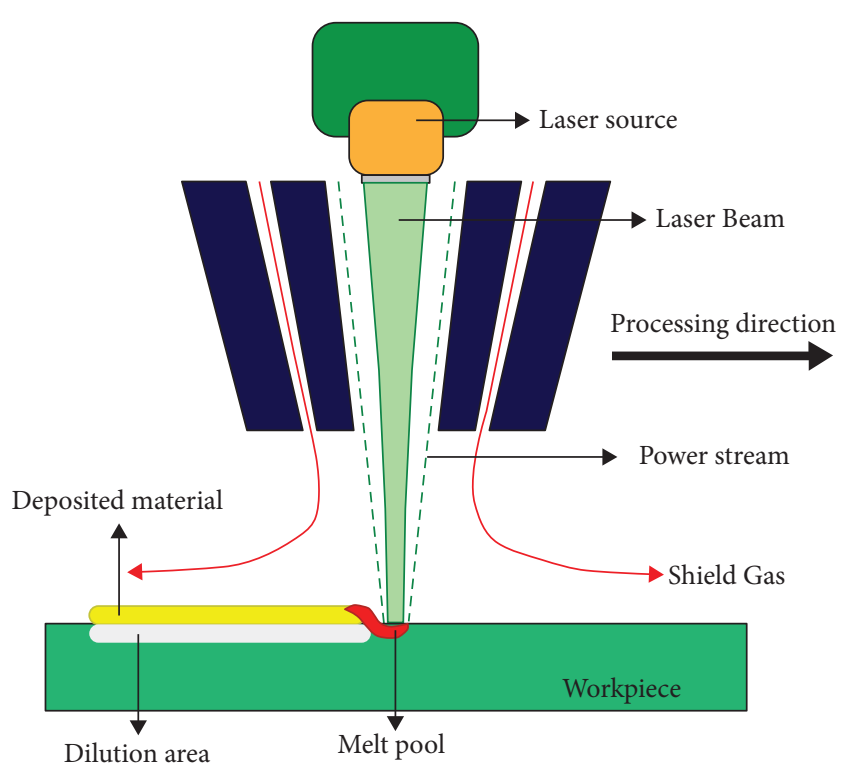

Figure 2: Graphic illustration of the LMD method.

relative thickness. This empowers the method to work close to complete thickness practical components and has reasonable monetary advantages [8].

2.5. Electron Beam Melting (EBM). EBM is another $3 \mathrm{D}$ printing fabrication process that is accepted to alter the production sector. Figure 5 shows the graphic illustration of the EBM method. The technique uses EB energy to liquefy the metal powder. The subsequent electron beam is utilized as the vital source of the whole procedure happens in a vacuum chamber. The vacuum guarantees extraordinary immaculateness by giving an oxygen-free condition and lessens the danger of hydrogen. When fabricating the component, a raised temperature of $700^{\circ} \mathrm{C}$ is kept up in the chamber to decrease leftover burdens and, consequently, twisting and warpage. The EB initially prewarms the powder layer through a greater sweep speed, tailed by liquefying the powder layer depending on the geometry characterized via CAD document. Each layer of a section is worked in dual steps in EBM. The external limit of the part is constructed first, which is alluded to as molding, and the powder inside the shape is dissolved along these lines to finish one layer. This method proceeds till the ideal $3 \mathrm{D}$ object is completely finished [9].

2.6. Solid-Based Systems. A solid-based system is a kind of $3 \mathrm{D}$ printing production process. Solid-based 3D printing methods use solids as the essential medium to make the component or model. They are totally diverse from the fluidbased photograph restoring process. They are likewise unique in relation to each other in that the essential type of strong materials in certain methods may come as fibers or wires, few as sheets or rolls, whereas others might be as pellets. An uncommon gathering of strong based $3 \mathrm{D}$ printing methods that utilize powder as the intermediate will be secured independently. The solid-based system can be classified into three major categories: Fused Deposition 


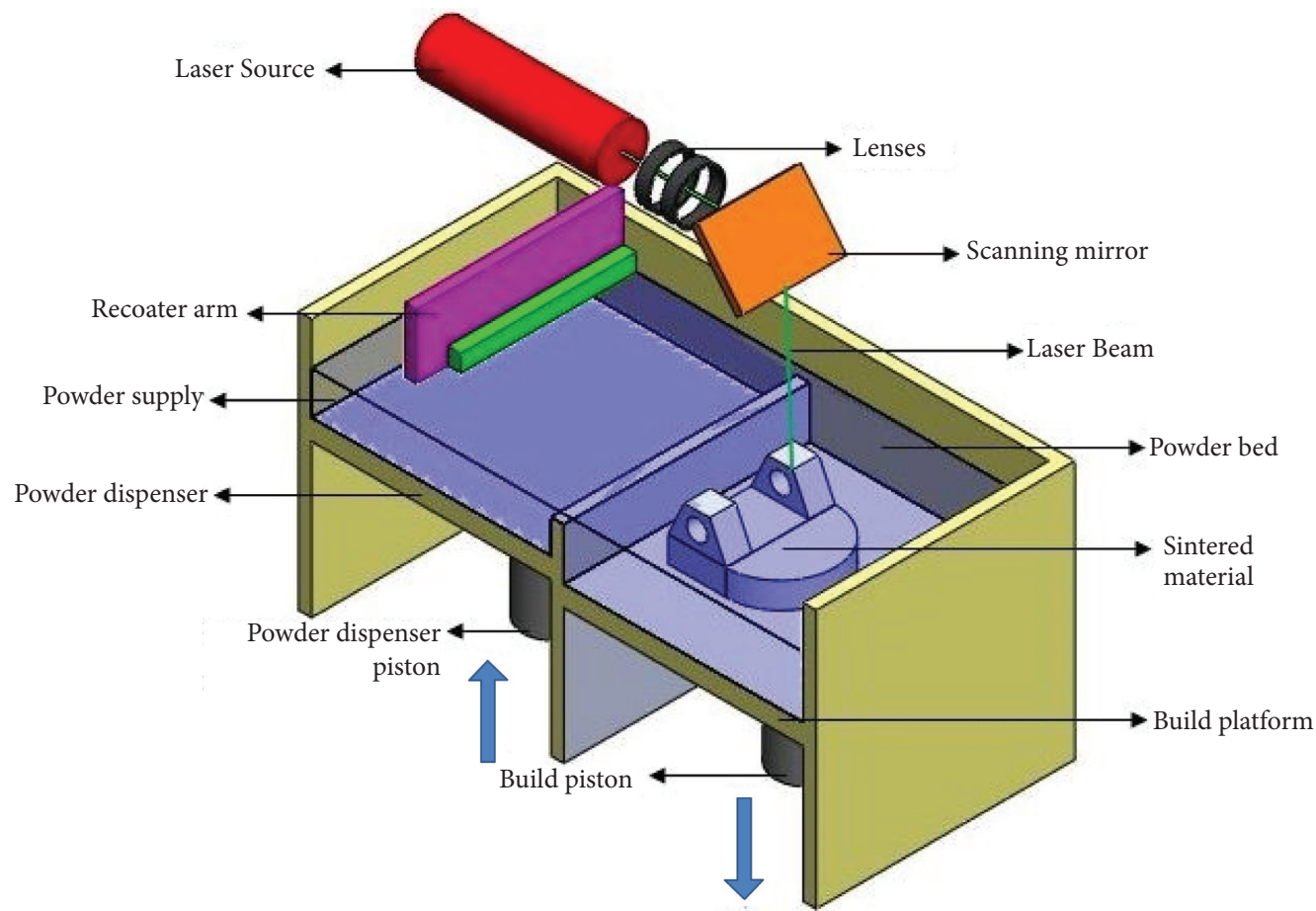

Figure 3: Graphic illustration of the DMLS method.

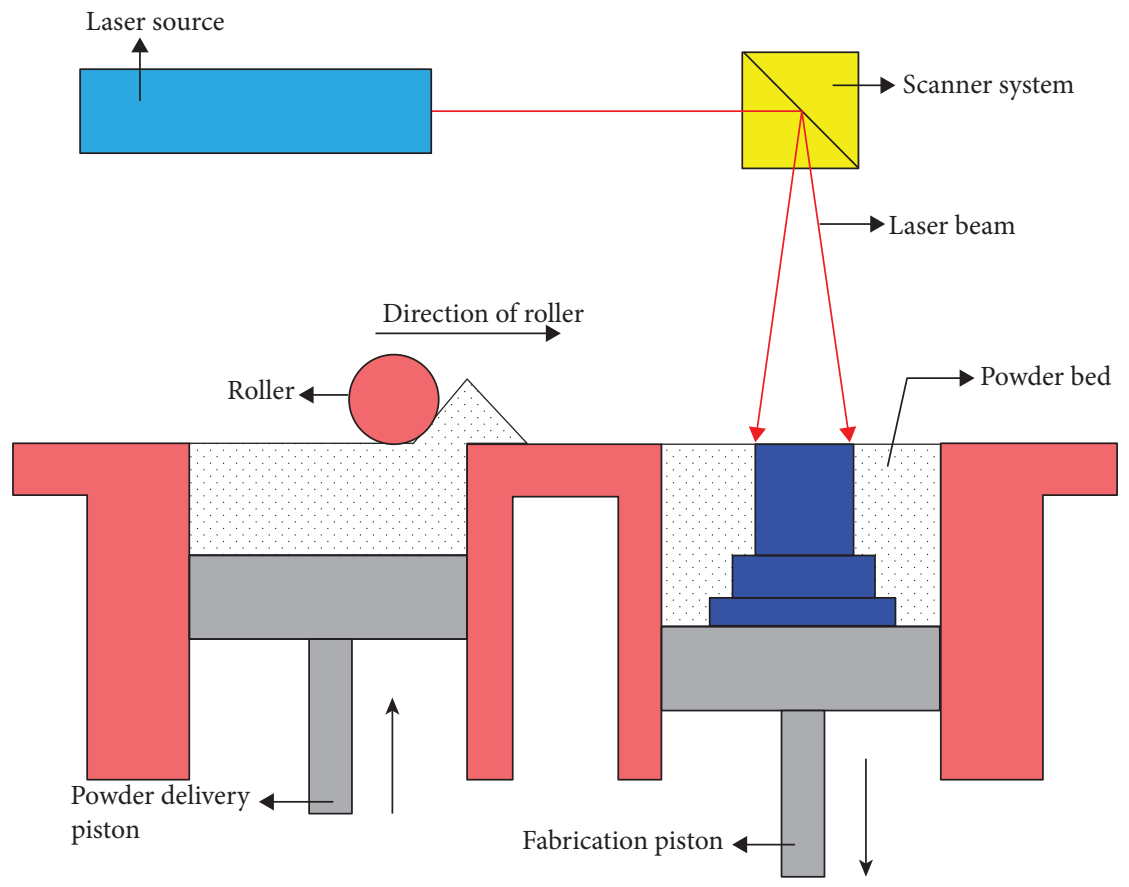

FIGURE 4: Graphic illustration of the SLM method.

Modeling (FDM), Electron Beam Freeform Fabrication (EBFF), and Wire Pulse Arc Additive Manufacturing (WPAAM).

2.7. Fused Deposition Modeling (FDM). A steady filament of a thermoplastic polymer is utilized to $3 \mathrm{D}$ print layers of materials in the FDM process. Figure 6 shows the graphic illustration of the FDM method. The fiber is heated by the sideways of the nozzle to show up at a semiliquid state and a short time later removed on the stage or on the head of late printed layers. The thermoplasticity of the polymer filament is a major property in this process, which permits the filament to consolidate in the course of printing and, a while later, to fix at room temperature in the rouse of printing. The deposit fatness, width and course of filament, and air 


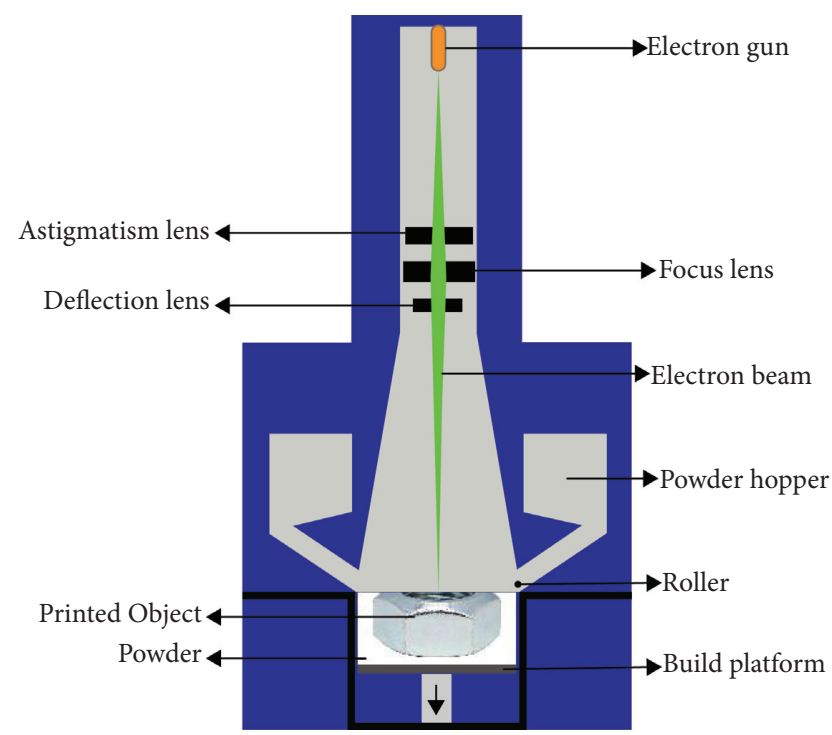

FIGURE 5: Graphic illustration of the EBM method.

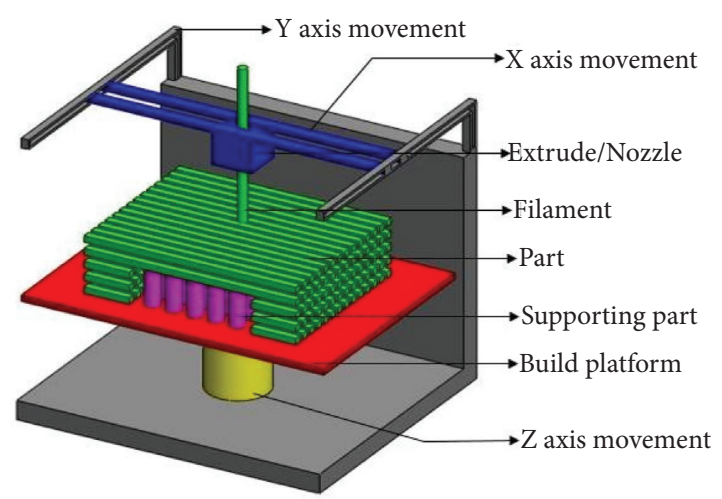

Figure 6: Graphic illustration of the FDM method.

opening are the essential getting ready limits that impact the mechanical properties of printed components. Amid layer meandering was viewed as the central driver of mechanical deficiency. Quick and ease operation techniques are the principal points of interest of FDM. In contrast, feeblemechanical behaviors, layer by layer arrival, powerless surface quality, and a foreordained number of thermoplastic materials are the guideline weaknesses of FDM. The headway of fiber-strengthened composites making use of FDM has fortified the mechanical properties of $3 \mathrm{D}$ components [10].

2.8. Electron Beam Freeform Fabrication (EBFF). EBFF is a developing cross-cutting process for manufacturing structural metal components. Figure 7 shows the graphic illustration of the EBFF method. The method can be utilized to construct a difficult, combined component in a layer-added substance style, although the more prompt result is for usage as a production method for including subtleties to segments manufactured from improved castings and forgings or plate items. EBFF utilizes a powerful electron beam in a vacuum domain $\left(1 \times 10^{-4}\right.$ torr or lower $)$.

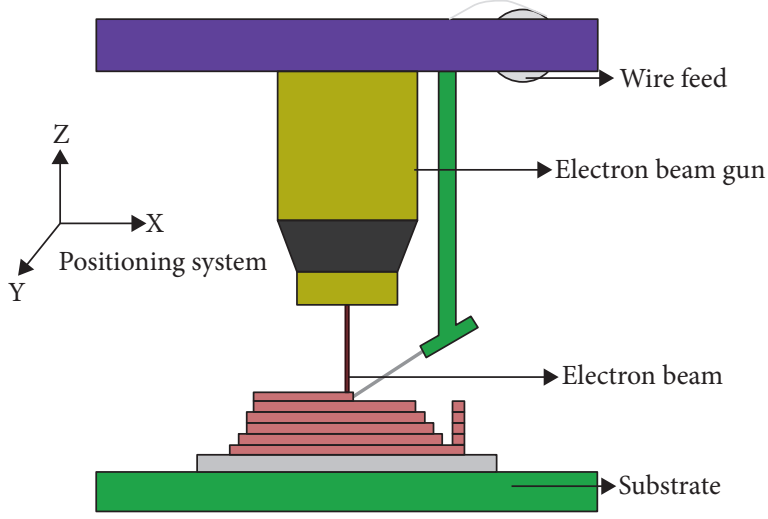

FIgURE 7: Graphic illustration of the EBFF method.

Wire feedstock is utilized because of troubles taking care of powder in a vacuum. In the meantime, the transporter gas utilized to help powder conveyance will be ionized in the electron beam. Activity in a vacuum guarantees a spotless procedure condition and disposes of the requirement for a consumable shield gas, as is normally utilized in laser affidavit methods.

The EBFF method is about $100 \%$ proficient in feedstock utilization and approaches $95 \%$ effectiveness in power use. The electron beam couples well with any electrically conductive material, containing profoundly intelligent composites, for example, aluminum and copper. An assortment of weldable composites can be prepared utilizing EBFF. Further improvement is required to decide whether nonweldable combinations can likewise be saved. Exhibited affidavit rates for EBFF are 330 to $2500 \mathrm{~cm}^{3} / \mathrm{hr}$ (20 to 150 $\mathrm{in}^{3} / \mathrm{hr}$ ), with a lower goal in the capacity to assemble fine subtleties. Investigations are arranged with fine-width wires to endeavor to build fine subtleties and huge distance across wires to expand affidavit rate. EBFF offers suitable answers to issues of testimony rate, process effectiveness, and material similarity for inclusion into the creation condition [11].

2.9. Wire Pulse Arc Additive Manufacturing (WPAAM). Recently, WAAM methodology got a fascination of production ventures because of the capacity of fabricating perplexing and huge metal segments with a high affidavit rate with roughly $100 \%$ material use. Figure 8 shows the graphic illustration of the WPAAM method. WAAM is a method of affidavit of liquid metal in a layer over layer structure to accomplish the last item. This advancement is done with an electric curve as a warmth source to soften the metal wire because of expanding request in the present market to grow new structures with huge profitability with less material waste and low hardware cost [12]. The mix of filler wires are made of the metal to keep the frame surface as the warm, and it is called as the regular welding method. for example, gas metal bend welding. The process has uncovered numerous points of interest, for example, the better BTF proportion contrasted with traditional assembling forms, hypothetically no dimensional cutoff points for the segment 


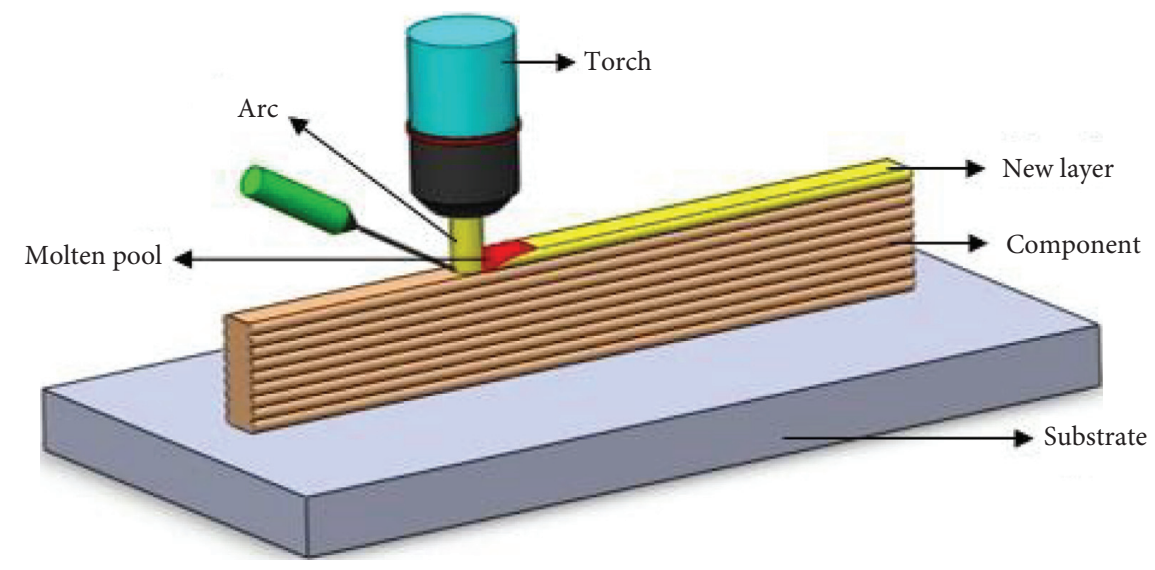

FIGURE 8: Graphic illustration of the WPAAM method.

producing and efficient method contrasted with powderbased methods when significant expense material is thought of [13].

2.10. Liquid-Based Systems. The liquid-based method involves diminishing or solidifying a photosensitive polymer when an impressive laser arrives at the tar. The principal classification of $3 \mathrm{D}$ printer makes object layers by specifically hardening a fluid sap known as photopolymer that solidifies when presented to laser or other light sources. Whatever photograph polymerization, 3D printers assembled object layers inside a tank of fluid. Then, others fly out a solitary layer of pitch and use ultraviolet light to set it strong before the following layer is added. A couple of 3D printers depend on the last-mentioned innovation and can blend a few distinctive photograph polymers in a similar print work, permitting them to yield objects produced using numerous materials. The liquid-based system can be classified into two major categories: stereolithography (SLA) and direct light processing (DLP) [14].

2.11. Stereolithography (SLA). Figure 9 shows the graphic illustration of the SLA method. The stereolithography technique was familiarized in the last part of the 1980s. Albeit numerous different methods have been created from that point forward, stereolithography stays the most impressive and adaptable method. It has the most noteworthy creation exactness, and an expanding number of materials that can be handled are opening up. Like most strong freestyle manufacture procedures, stereolithography is an added substance creation process that permits manufacturing parts from a PC helped plan (CAD) document. The production of 3D substances via stereolithography depends on the spatially controlled hardening of a fluid tar by photopolymerization. Employing a PC controlled laser beam or a computerized light projector with a PC driven structure stage, an example is lit up on the outside of a tar. Thus, the pitch in the example is cemented to a characterized profundity, making it hold fast to a help stage. After photographing polymerization of the principal layer, the stage is moved away from the surface and the assembled

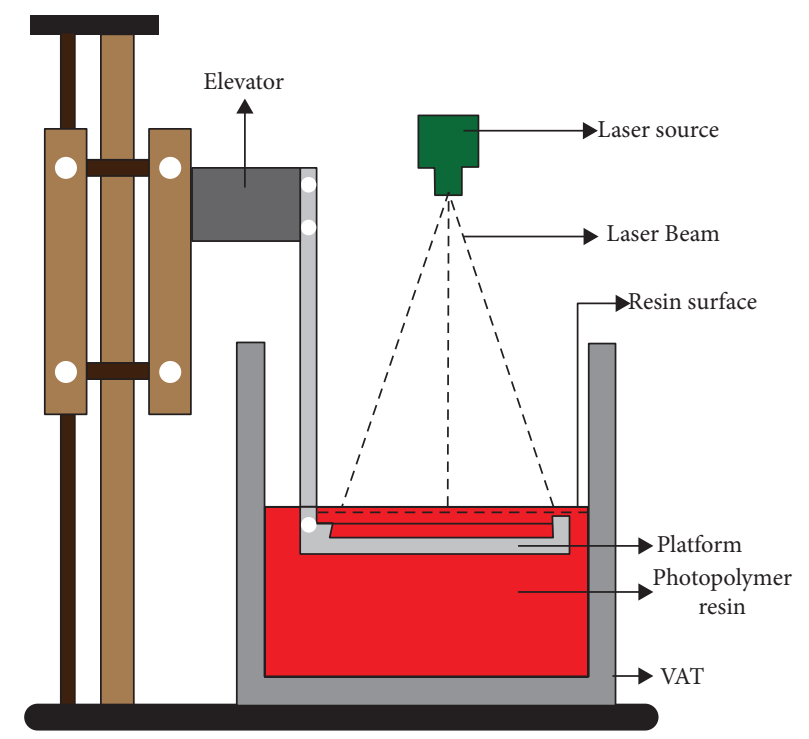

Figure 9: Graphic illustration of the SLA method.

layer is recoated with fluid tar. An example is then restored in this subsequent layer. As the profundity of restoring is marginally bigger than the stage step stature, greater adherence to the principal layer is guaranteed. These means are rehashed to develop a strong, three-dimensional article. In the wake of depleting and washing-off abundance pitch, an as-manufactured structure is got [15].

2.12. Direct Light Processing (DLP). Digital light processing (DLP) built 3D printing uses projection light to polymerize materials to acquire the preplanned structures. Figure 10 shows the graphic illustration of the DLP method. This method has critical focal points in printing goal, proficiency, and working conditions. Consequently, it can give numerous great highlights to the items. The DLP and laser helped printing strategies smear photopolymerization responses. These $3 \mathrm{D}$ printing stages have critical contrasts in printing instrument, speed, material determination, and goal. This strategy utilizes a lot of chipsets dependent on optical miniaturized scale electromechanical innovation to 


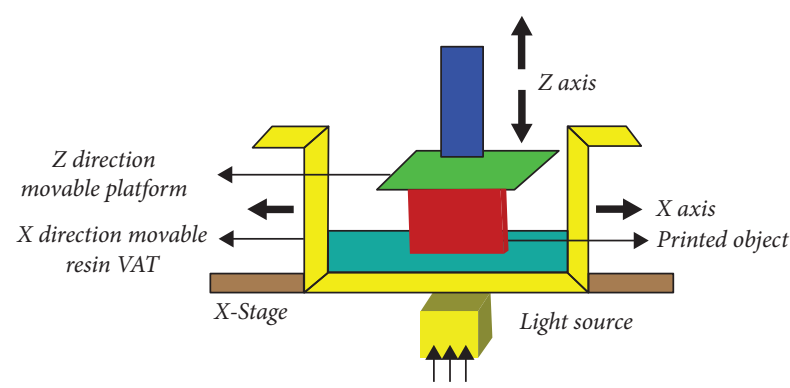

FIgURE 10: Graphic illustration of the DLP method.

the method employed light sources of photosensitive materials.

The fundamental utilitarian component is a computerized small scale reflect gadget (DMD), which comprises a gathering of micron-sized, controllable mirrors. The mirror turns to control the way of light and afterward venture it onto the photosensitive sap through working. The customary exhibits have an enormous number of mirrors, from almost a million mirrors to in excess of 2 million. Then again, the pixel dispersing of the miniaturized scale reflect is just a couple of microns or twelve microns. The goal of the DLP put together $3 \mathrm{D}$ printing based with respect to the projection plane balanced by DMD and focal point. Subsequently, the DLP printing procedure has a moderately high goal, for the most part at the micron scale [16].

\section{Materials Used in 3D Printing}

Each material plays a major role in different applications. Based on the applications of the components, any one of the suitable materials can be selected. Some of the materials utilized for numerous usages in 3D printing techniques are shown in Figure 11.

3.1. Metals Used in 3D Printing. Stainless steels are the most generally utilized metal in $3 \mathrm{D}$ printing. Stainless steels could have multiple uses for extraordinary strength and hardness circumstances, mainly for tools and molding uses. Stainless steels are predominantly complex to $3 \mathrm{D}$ printing parameters [10]. Gold is one of the rare metals utilized as raw material in selective laser melting. The major reason to choose gold as a raw material is its excellent thermal conductivity. The selective laser melting method uses gold as a raw material to manufacture jewels and ornaments. Silver is one of the metals utilized as raw material in the SLM method [17]. It permits the production of jewelry and ornaments with difficult designs, in any case not plausible with regular methods. In addition, it assists with diminishing the expense of creation by out-staging the utilization of costly shapes and bites the dust and by permitting unemployed powder to be recycled for the following group of fabrication [18]. Titanium is one of the major important raw materials used in the SLM and EBM methods. This material finds major applications in the biomedical field [19].
3.2. Ceramics Used in 3D Printing. Ceramics find extensive applications in aerospace, biomedical engineering, chemical industry, electronics, and machinery despite its outstanding mechanical, electrical, chemical, and thermal behaviors. Ceramics-based components can be fabricated via selective laser melting and fused deposition modeling techniques [20]. Ceramics such as $\mathrm{Al}_{2} \mathrm{O}_{3}$ [21], $\mathrm{ZrO}_{2}$ [22], $\mathrm{LiO}_{2}$ [23], $\mathrm{SiO}_{2}$ [24], $\mathrm{SiC}$ [25], $\mathrm{Si}_{3} \mathrm{~N}_{4}$ [26], and PZT [27] are used as raw materials to produce novel lightweight components such as turbine rotor, gear wheels, complex-shape parts, and different transducers.

3.3. Polymers Used in 3D Printing. Polymers find extensive applications in engineering industries despite their less weight and superior properties. Polymers-based parts can be manufactured easily via the fused deposition technique. Examples of polymers are nylon [28], resin [29], polylactic acid [30], polyethylene terephthalate [31], high impact polystyrene [32], and acrylonitrile.

Butadiene Styrene [33] finds numerous applications in $3 \mathrm{D}$ printing manufacturing industries. Polymer components such as crane hooks, gear wheels can be fabricated via $3 \mathrm{D}$ printing with desired properties.

3.4. Applications of 3D Printing in Engineering Industries. As the possible applications for 3D printing rise, engineering industries are starting to discover approaches to make new plans of action and openings with the methods. 3D printing technology possesses a major role in the major three engineering industries: aerospace, automotive, and biomedical. The demand for 3D printing technology in these three industries rapidly increases day by day because of its numerous advantages.

3.5. 3D Printing Applications in Aerospace Industry. 3D printing methods are perfect for manufacturing aerospace parts as they want little groups of parts, which have difficult geometries, vital for airflow and heat indulgence capacities. Besides, on-request and on-location fabricating should have been set up for space explorers to deliver parts for fixing or supporting space stations. Additionally, $3 \mathrm{D}$ printing is equipped for delivering leaves behind a low density-to-quality proportion, which is important for planes and space transports. Meanwhile, the materials utilized in the airplane business are costly, and 3D printing forms are identified as having the least waste material. $3 \mathrm{D}$ printing has become mainstream among makers in the aeronautic trade [34]. Aircraft parts should be lighter in weight and contemporary good strength and firmness-to-weight ratios to lessen expenditures and expulsions [10]. Aircraft have a long working presence of as long as 30 years. Possession of long-standing components acquires an eminent expense of stock. However, 3D printing is equipped for gathering components on request, along these lines reducing the upkeep time [35]. Nickel-based alloys and Ti-6Al-4V are materials utilized in aerospace components manufacturing. These materials possess superior tensile properties, hardness, destruction tolerance, and corrosion/ 


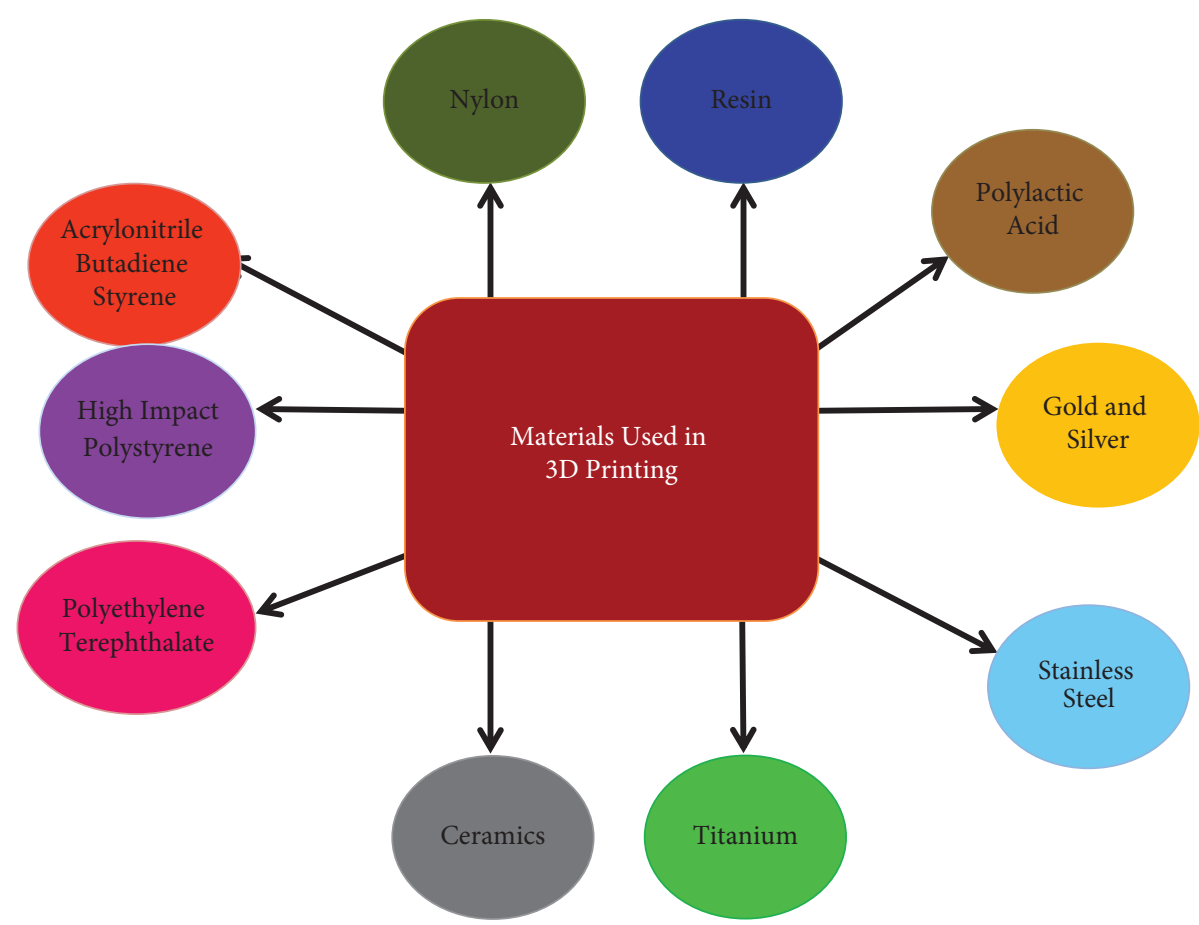

Figure 11: Types of materials used in 3D printing.

oxidation opposition [1]. Abrasive turbine blade tips can be manufactured via the SLM technique by using nickel-based superalloy as a raw material [36]. Airplanes fuel nozzles and brackets inside the traveler cabin can easily manufactured via 3D printing methods [37]. In aerospace productiveness, 3D printing method can possibly fabricate less weight components and enhance and intricate geometries, which could lessen energy necessity and resources.

At the same time, using the $3 \mathrm{D}$ printing method could speed fuel backup funds because it can reduce the material utilized to fabricate aerospace's components. Moreover, the 3D printing method has been broadly smeared to fabricate the additional pieces of a few aviation parts, such as engines. The engine components can be effectively impaired, which need normal replacement. Consequently, the 3D printing method is a virtuous key for acquiring such additional components [38]. Nonmetal 3D printing processes such as stereolithography and fused deposition modeling are utilized for the fast prototyping of components and producing installations and insides prepared via plastics, earthenware production, and composite materials. Together metallic and nonmetallic components for aviation applications can be produced or fixed utilizing $3 \mathrm{D}$ printing such as aero engine parts, turbine blades, and heat exchangers [39, 40].

3.6. 3D Printing Applications in Automotive Industry. Difficult and less weight-to-quality proportion is a need for components in the automobile. 3D printing is not just utilized for prototyping for automotive components; however, its favorable circumstances have likewise made it ready to be utilized for $3 \mathrm{D}$ printing of real parts and vehicles [41]. For Instance, optimize utilized LENS to decrease the material, time, and cost of fabricating red bull racing vehicle parts comprising drive shaft bugs and suspension mounting sections [42]. 3D printing methods in the automobile sector authorize the organization of effort dissimilar choices and stress straight in the enhancement phases, inciting perfect and successful automobile design [43]. Aluminum metal matrix composites (AMCs) have widespread $3 \mathrm{D}$ printing applications in the automotive sector because of their bitter properties. Using the selective laser melting method, automobile components can be fabricated easily with desired properties using AMCs as a raw material [44]. Multifaceted automobile components of different dimensions can be fabricated via the selective laser melting method using metals and alloys as raw materials [45]. Nowadays, using the 3D printing method, it is workable for vehicle fabricators to design and make one exclusive vehicle prototype that could fulfill the assorted perceptions and inclinations of clients in the marketplace. Likewise, the 3D printing method has prepared it workable for some vehicle fabricating companies to contend decently with their adversaries in the market. Besides, by utilizing the printing method to make vehicles, it has been workable for vehicle makers to spare generous expenses and work that would somehow be brought about when utilizing the conventional vehicle gets designs together [46]. Car roofs, fenders, and windshield frames can be manufactured using carbon fiber as a raw material. Using the selective laser melting methods, exhausts, emissions, pumps, valves within the fluid handling system, windbreakers, and bumpers could be manufactured easily [47].

3.7. 3D Printing Applications in Biomedical Field. Donor deficiencies for organ replacements are a significant clinical test around the world. Probable dangers that are definitely 
experienced with conventional techniques incorporate intricacies, optional wounds, and constrained source donors. 3D printing method embraces the possibility to illuminate these impediments; it may be utilized to quickly produce customized tissue building frameworks, fix tissue surrenders in situ with cells, and even straightforwardly print tissue and organs [48]. Biomedical uses, such as tissues, frameworks, and obsession gadgets, have explicit manufacturing parts that ought to be thought of. For biomedical uses, utilizing these $3 \mathrm{D}$ printing techniques without inflexible help structures is firmly suggested [49]. Present progressions in tissue designing and recovery, remedial conveyance, clinical gadget manufacturing, employable administration, and arranging guarantee that 3D printing will keep on assuming an inexorably significant job later on for healthcare [50]. Medical 3D printing was previously an eager impractical imaginary. Period and endeavor make it unpretentious. At present, the $3 \mathrm{D}$ printing process expresses a foremost option to support pharmaceutical and clinical organizations with making more obvious medications, permitting a fast making of clinical embeds, and altering the mode that experts and specialists plan methodology. Patient precise 3D-printed anatomical replicas are rotating out to be gradually helpful devices in the current act of accurateness medication and for tailored medicines. Later on, 3D-printed implantable organs will be accessible, declining the holding up archives and intensifying the number of lives spared. Added substance production for human services is still predominantly in evolution. However, it is now applied from multiple points of view in the clinical field that previously reeling under tremendous tension concerning the ideal execution and decreased costs will raise extraordinary benefits from this great as-gold novelty [51].

\section{Conclusions}

Nowadays, the $3 \mathrm{D}$ printing method is one of the engineering industries. It offers numerous advantages to the industries. Along these lines, more data are predictable to advance the methods to improve the reception of $3 \mathrm{D}$ printing methods. More data about the 3D printing method will assist businesses with upgrading and improving the framework of 3D printing innovation. Thus, this article overviewed the types of $3 \mathrm{D}$ printing production methods, materials, and usages in various industries. This article will be helpful for academicians, researchers, and scientists to do much research on $3 \mathrm{D}$ printing production techniques and suitable materials for particular applications.

\section{Data Availability}

The data used to support the findings of this study are included in the article.

\section{Conflicts of Interest}

The authors declare that there are no conflicts of interest regarding the publication of this article.

\section{References}

[1] S. C. Joshi and A. A. Sheikh, "3D printing in aerospace and its long-term sustainability," Virtual and Physical Prototyping, vol. 10, no. 4, pp. 175-185, Article ID 1111519, 2015.

[2] N. Shahrubudin, T. C. Lee, and R. Ramlan, "An Overview on 3D printing technology: technological, materials, and applications," Procedia Manufacturing, vol. 35, pp. 1286-1296, 2019.

[3] T. Singh, S. Kumar, and S. Sehgal, "3D printing of engineering materials: a state of the art review," Materials Today: Proceedings, vol. 28, no. 3, pp. 1927-1931, 2020.

[4] K. M. Pradeep and P. Senthil, "Prediction of in-plane stiffness of multi-material 3D printed laminate parts fabri- cated by FDM process using CLT and its mechanical behaviour under tensile load," MaterToday Comm, vol. 23, Article ID 100955 , 2020.

[5] M. Quanjin, M. R. M. Rejab, M. S. Idris, N. M. Kumar, M. H. Abdullah, and G. R. Reddy, "Recent 3D and 4D intelligent printing technologies: a comparative review and future perspective," Procedia Computer Science, vol. 167, pp. 1210-1219, 2020.

[6] M. A. Mahmood and C. Andrei, "Popescu and ion N. Mihailescu. "Metal matrix composites synthe- sized by laser-melting deposition: a review," Materials, vol. 13, no. 11, p. 2593, 2020.

[7] F. Mangano, L. Chambrone, C. Miller, V. R. Noort, P. Hatton, and C. Mangano, "Direct metal laser sintering titanium dental implants: a review of the current literature," International Journal of Biology, vol. 2014, Article ID 461534, 11 pages, 2014.

[8] C. Y. Yap, C. K. Chua, Z. L. Dong et al., "Review of selective laser melting: materials and applications," Applied Physics Reviews, vol. 2, no. 4, Article ID 041101, 2015.

[9] J. Sweels and F. E. Waiyy, "Laser and electron-beam powderbed additive manufacturing of metal- lic implants: a review on processes. Mater and Desig," Journal of Orthopaedic Research, vol. 34, pp. 369-385, 2016.

[10] P. Gurusamy, T. Sathish, V. Mohanavel et al., "Finite element analysis of temperature distribution and stress behavior of squeeze pressure composites," Advances in Materials Science and Engineering, vol. 2021, Article ID 8665674, 9 pages, 2021.

[11] K. Taminger and R. Hafley, "Electron beam freeform fabrication: a rapid metal deposition process," in Proceedings of the 3rd Annual Automotive Composites Conference, pp. 1-6, Troy, MI, USA, September 2003.

[12] T. Kodati, Y. R. P. Subhashcvt, and K. L. Narayana, "Optimization of mechanical properties of wire arc additive manufactured specimens using grey-based taguchi method," Journal of Critical Reviews, vol. 7, no. 9, pp. 808-817, 2020.

[13] T. Sathish, S. Tharmalingam, V. Mohanavel et al., "Weldability investigation and optimization of process variables for TIG-welded aluminium alloy (AA 8006)," Advances in Materials Science and Engineering, vol. 2021, Article ID 2816338, 17 pages, 2021.

[14] A. Ramya and L. V. Sai, "3D printing technologies invarious applications," International Journal of Mechanical Engineering \& Technology, vol. 7, no. 3, pp. 396-409, 2016.

[15] F. P. W. Melchels and D. W. Grijpma, "A review on stereolithography and its applications in biomedical engineering," Biomaterials, vol. 31, no. 24, pp. 6121-6130, 2010.

[16] J. Zhang, Q. Hu, S. Wang, J. Tao, and M. Gou, "Digital light processing based three- dimensional printing for medical applications," International Journal of Bioprinting, vol. 6, no. 1, 2019. 
[17] J. Jhabvala, E. Boillat, and R. Glardon, "On the use of EBSD analysis to investigate the microstructure of gold samples built by selective laser melting," Gold Bulletin, vol. 44, no. 2, pp. 113-118, 2011.

[18] E. O. Olakanmi, R. F. Cochrane, and K. W. Dalgarno, "A review on selective laser sintering/melting (SLS/SLM) of aluminium alloy powders: processing, microstructure, and properties," Progress in Materials Science, vol. 74, pp. 401-477, 2015.

[19] J. NiH. Ling et al., "Three-dimensional printing of metals for biomedical applications," Materials Today Bio, vol. 3, Article ID 100024, 2019.

[20] Z. ChenZ. Li et al., "3D printing of ceramics: a review," Journal of the European Ceramic Society, vol. 39, no. 4, pp. 661-687, 2019.

[21] W. Jan, Y. C. Hagedorn, W. Meiners, and K. Wissenbach, "Additive manufac- turing of $\mathrm{ZrO} 2-\mathrm{Al} 2 \mathrm{O} 3$ ceramic components by selective laser melting," Rapid Prototyping Journal, vol. 19, no. 1, pp. 51-57, 2013.

[22] Y. C. Hagedorny, N. Balachandrann, W. Meinersw, and P. Wissenbachk, "SLM of net-shaped high strength ce- ramics: new opportunities for producing dental restorations," in Proceedings of the Solid Freeform Fabrication Symposium, pp. 8-10, Austin, Texas, August 2011.

[23] C. Steidle, D. Klosterman, R. Chartoff, G. Graves, and $\mathrm{N}$. Osborne in Proceedings of the 44th International SAMPE Symposium and Exhibition, Long Bach, CA, USA, May 1999.

[24] M. Pfaffingerm and S. Gmeinerr, "Thermal debinding of ceramic-filled photopolymers," Materials Science Forum Trans Tech Publication, vol. 825-826, pp. 75-81, 2015.

[25] N. Travitzky, H. Windsheimer, and T. Fey, "Preceramic paper-derived ceramics," Journal of the American Ceramic Society, vol. 91, no. 11, pp. 3477-3492, 2008.

[26] N. Xu, X. Ye, D. Wei et al., "3D artificial bones for bone repair prepared by computed tomography-guided fused deposition modeling for bone repair," ACS Applied Materials \& Interfaces, vol. 6, no. 17, Article ID 14963, 2014.

[27] M. Allahverdi, M. Jafari, A. Safari, and S. C. Danforth, "Processing of advanced electroceramic components by fused deposition technique," Journal of the European Ceramic Society, vol. 21, no. 10-11, pp. 1485-1490, 2001.

[28] X. Wang, M. Jiang, Z. Zhou, J. Gou, and D. Huic, "3D printing of polymer matrix composites: a review and prospective," Composites Part B: Engineering, vol. 110, pp. 442-458, 2017.

[29] H. Quan, T. Zhang, H. Xu, S. Luo, J. Nie, and X. Zhu, "Photocuring 3D printing technique and its challenges," Bioact Mater, vol. 5, no. 1, pp. 110-115, 2020.

[30] M. Caminero, J. Chacón, E. Núñe, J. Reverte, and J. Becar, "Additive manufacturing of PLA-based composites using fused filament fabrication: effect of gn reinforcement on mechanical properties, dimensional accuracy and texture," Polymers, vol. 11, no. 5, 2019.

[31] K. Tappa and U. Jammalamadaka, "Novel biomaterials used in medical 3D printing techniques," Journal of Functional Biomaterials, vol. 9, no. 1, 2018.

[32] D. Moises, B. Lopez, and R. Ahmad, "Tensile mechanical behaviour of multi-polymer sandwich structures via fused deposition modelling," Polymers, vol. 12, no. 3, 2020.

[33] M. M. Padzi, M. M. Bazin, and W. M. W. Muhamad, "Fatigue characteristics of 3D printed acrylonitrile Butadiene Styrene (ABS)," IOP Conference Series: Materials Science and Engineering, vol. 269, Article ID 012060, 2017.

[34] M. Mehrpouya and B. Fotovvati, D. Amir, V. Alireza, S. E. Sattar, and A. Gisario, "The potential of additive manufacturing in the smart factory," Review. Applied Science, vol. 9, no. 18, pp. 1-34, 2019.

[35] H. K. Siavash, P. Jouni, and H. Jan, "Additive manufacturing in the spare parts supply chain," Computers in Industry, vol. 65 , no. 1 , pp. 50-63, 2014.

[36] D. Suman, P. F. Timothy, D. Gregory, E. B. Lawrence, J. B. Joseph, and L. B. David, "Direct laser fabrication of superalloy cermet abrasive turbine blade tips," Materials \& Design, vol. 21, no. 2, pp. 63-73, 2000.

[37] C. Buchanan, "Metal 3D printing in construction: a review of methods, research, applications, opportunities and challenges," Engineering Structures, vol. 180, pp. 332-348, 2019.

[38] Y. Cheng and Y. L. Tolyc, "Advanced 3D printing technologies for the aircraft industry: a fuzzy systematic approach for assessing the critical factors," The International Journal of Advanced Manufacturing Technology, vol. 105, pp. 4059-4069, 2019.

[39] L. Yin, X. Tian, and D. Li, "Design and characterization of radar absorbing structure based on gradient-refractive-index metamaterials," Composites Part B: Engineering, vol. 132, pp. 178-187, 2018.

[40] E. Turco, M. Golaszewski, I. Giorgio, and F. D’Annibale, "Pantographic lattices with non-orthogonal fibres: experiments and their numerical simulations," Composites Part B: Engineering, vol. 118, pp. 1-14, 2017.

[41] H. G. Kia, N. Huang, J. P. Spicer, and J. F. Arinez, "Additive Manufacturing of a Unibody Vehicle," U.S. Patent No. 10,022,912, Patent and Trademark Office, Washington, DC, USA, 2018.

[42] G. Nannan and C. L. Ming, "Additive manufacturing: technology, applications and research needs," Front MechEngg, vol. 8, pp. 215-243, 2013.

[43] R. Maghnani, “An exploratory study: the impact of additive manufacturing on the automobile industry," J CurreEnggTechn, vol. 5, no. 1-4, 2015.

[44] S. Dadbakhsh, L. Hao, P. G. E. Jerrard, and D. Z. Zhang, "Experimental investigation on selective laser melting behaviour and processing windows of in situ reacted $\mathrm{Al} / \mathrm{Fe} 2 \mathrm{O} 3$ powder mixture," Powder Technology, vol. 231, pp. 112-121, 2012.

[45] M. A. Ryder, D. A. Lados, G. S. Iannacchione, and A. M. Peterson, "Fabrication and properties of novel polymermetal composites using fused deposition modeling," Composites Science and Technology, vol. 158, no. 43-50, 2018.

[46] A. S. Elakkad, "3D technology in the automotive industry," International Journal of Engineering Research, vol. V8, no. 11, pp. 248-251, 2019.

[47] R. Manghnani, “An exploratory study: the impact of additive manufacturing on the automobile indus- try," International Journal of Current Engineering and Technology, vol. 5, no. 5, pp. 3407-3410, 2015.

[48] Q. Yan, H. Dong, J. Su, and J. Han, B. Song and Q. Wei, "A review of 3D printing technology for medical applications," Engineering, vol. 4, no. 5, pp. 729-742, 2018.

[49] F. S. S. Seyed, G. Samira, M. Mehdi et al., "A review on powderbased additive manufacturing for tissue engineering: selective laser sintering and inkjet 3D printing," Science and Technology of Advanced Materials, vol. 16, no. 3, Article ID 33502, 2015.

[50] P. Ahangar, M. E. Cooke, and M. H. Weber, "Current biomedical applications of $3 \mathrm{D}$ printing and additive manufacturing," Applied Sciences, vol. 9, no. 8, 2019.

[51] A. Aimar, P. Augusto, and B. Innocenti, "The Role of 3D printing in medical applications: a state of the art," Journal of Healthcare Engineering, vol. 2019, Article ID 5340616, 10 pages, 2019. 